\title{
O DIREITO QUE SE PRODUZ EM COMUM: as "regras de convivência" nas experiências do projeto cantinas solidária da Incubadora de Iniciativas da Economia Popular e Solidária da UEFS
}

\author{
Flávia Almeida Pita \\ Universidade Estadual de Feira de Santana (UEFS) \\ Universidade Federal Fluminense (UFF)
}

\begin{abstract}
RESUMO
No projeto Cantinas Solidárias, da Incubadora de Iniciativas da Economia Popular e Solidária da Universidade Estadual de Feira de Santana (Bahia, Brasil), grupos de trabalhadoras(es) vivenciam a experiência de produzir e comercializar alimentos em cantinas da Universidade, transformadas em espaços pedagógicos daquele programa de extensão e pesquisa. Pretende-se apresentar, neste texto, a experiência de acompanhamento do processo de normatização autogestionária do trabalho coletivo, que envolve a reflexão sobre as regras produzidas pelas(os) trabalhadores(as), a sua percepção como um fenômeno de caráter jurídico não estatal e sua importância para a construção do comum a partir do trabalho associado. Configurada a partir dos princípios da pesquisa participante, a proposta, muito embora não prescinda de reflexões teóricas sobre a caracterização de tal fenômeno normativo como jurídico, centra-se sobretudo na preocupação de identificar, a partir da práxis, as características e os sentidos que assumem, no trabalho coletivo autogestionário, as regras produzidas espontaneamente pela convivência, assim como o papel que podem representar nas desafiadoras lutas populares por formas contra-hegemônicas de reprodução da vida.
\end{abstract}

Palavras-chave: Direito. Trabalho Coletivo Autogestionário. Comum. Normatização.

\section{THE RIGHT THAT IS PRODUCED IN COMMON: "co-habitation rules" in the experiences of the solidarity canteens project of the UEFS Popular and Solidarity Economy Initiative Incubator}

\begin{abstract}
In the "Solidarity Canteens", a project of the Incubator of Popular and Solidarity Economy (Universidade Estadual de Feira de Santana, State of Bahia, Brazil), groups of workers experience the production and commercialization of food in canteens of the University, transformed into pedagogical spaces of that extension and research program. The aim of this paper is to present the experience of monitoring the self-management lawmaking process of collective work, that involves reflection on the rules produced by the workers, its perception as a non-state legal phenomenon and its importance for the construction of the common from the associated work. Based on the participant research principles, the proposal, although not without theoretical reflections on the characterization of such normative phenomenon as juridical, focuses mainly on the concern to identify, from the praxis, the characteristics and the senses that assume, in the self-managed collective work, the spontaneous rules produced by the coexistence, as well as the role they can play in the challenging popular struggles for counter-hegemonic forms of life reproduction.

Keywords: Law. Self-management Collective Work. Common. Lawmaking process.
\end{abstract}




\section{INTRODUÇÃO}

Neste texto apresento reflexões a partir de experiências de pesquisa e extensão realizadas no âmbito da Incubadora de Iniciativas da Economia Popular e Solidária da Universidade Estadual da Feira de Santana - IEPS-UEFS. Integro o coletivo interdisciplinar deste programa de pesquisa e extensão desde 2010, cujas ações desenvolvem-se em torno da ideia de "um caminho de diálogo potencializador da resistência e de experiências voltadas à consolidação de um novo modo de produção e organização do trabalho e da sociedade", enfatizando-se "a mobilização e fortalecimento das organizações sociais que trabalham de modo coletivo, cooperativo, associativo e autogestionário, considerando a economia popular e solidária ${ }^{1}$ enquanto movimento de economia política dos setores populares" (IEPS-UEFS 2011). Em seu âmbito desenrolam-se, de forma simultânea, diversos projetos que, sob a perspectiva da pesquisa participante (Brandão 1984), combinam pesquisa e extensão voltadas para a busca de resposta para os problemas e lutas das classes populares.

A partir desse mesmo espaço empírico, também desenvolvo, desde 2016, pesquisa de doutoramento junto ao Programa de Pós-Graduação em Sociologia e Direito da Universidade Federal Fluminense, em que tenho tido a oportunidade de sistematizar e aprofundar um conjunto de ações que foram e vêm sendo desenvolvidas pela Incubadora em torno da organização jurídica de iniciativas de trabalho coletivo autogestionário. Sob o título provisório de "Direito e colonialidade do poder: um olhar a partir do problema da personificação jurídica de grupos de trabalho associado da economia popular e solidária no Brasil", a pesquisa tem como objetivo principal "investigar a questão da personificação jurídica de grupos de economia popular e solidária, a partir da experiência dos grupos envolvidos nos Projetos Cantinas Solidárias, fazendo desta perspectiva uma janela para pensar o papel do direito de matriz europeia no bojo de relações de trabalho associado no nordeste brasileiro".

O Projeto Cantinas Solidárias, iniciado em 2013, envolve a "incubação"2 de iniciativas populares, a que se oportuniza a produção e comercialização de alimentos em duas cantinas do

\footnotetext{
${ }^{1}$ São diversos os embates teóricos em torno do escolhemos denominar economia popular e solidária (vide Lechat 2002 , Gago 2018, Aguilar 2018). A complexidade da realidade que o conceito tenta abarcar explica a sua equivocidade. De todo modo, fala-se aqui, em linhas gerais, de arranjos econômicos cujos traços característicos centrais, não obstante sua heterogeneidade, são a organização de coletivos de trabalhadores(as) que têm como pretensão atuar de forma autogestionária, num movimento de diferenciação da lógica da exploração do trabalho pelo capital. Fazem parte do discurso envolvido nesta forma de trabalho princípios como solidariedade (em oposição ao individualismo e competitividade das práticas hegemônicas), gestão democrática, propriedade coletiva dos meios de produção.

${ }^{2}$ Em sua "Carta de Princípios", a IEPS define incubação como "processo político, prático-educativo de organização e acompanhamento sistêmico a grupos envolvidos no processo econômico popular e solidário". Adotam-se "os fundamentos da economia popular e solidária possibilitando a integração solidária dos sujeitos, colocando como valores principais o trabalho coletivo, o conhecimento e o atendimento às necessidades sociais da população" (IEPS-UEFS, 2011).
} 
campus central da UEFS, transformadas em espaços pedagógicos da Incubadora. O projeto encontra-se na sua quarta edição, tendo passado pelos espaços dois grupos urbanos da cidade de Feira de Santana (entre 2013 e 2016) e dois grupos rurais (um deles de uma comunidade quilombola), que iniciaram sua participação no projeto em 2016 e 2017 e lá prosseguem até o momento. Muito embora as vivências com os grupos tenham aberto perspectivas de pesquisa em várias áreas, no meu caso a preocupação central tem sido a observação do modo como se dá a sua organização jurídica, sob dois prismas diferentes: por um lado, a sua convivência com os limites, exigências e peculiaridades do ordenamento jurídico estatal, especialmente no que diz respeito à questão da personificação jurídica (ou, na expressão mais corrente, da sua "formalização"- isto é, a facejurídica mais evidente dos complexos conceitos de formalidade/informalidade ${ }^{3}$ ); por outro, o modo como o fenômeno jurídico acontece, à revelia do Estado, na auto-organização do trabalho e da convivência no comum que resulta deste tipo de experiência popular e coletiva.

É dessa segunda perspectiva que me aproximo neste texto, tratando da experiência de acompanhamento do processo de normatização autogestionária do trabalho coletivo, sub-projeto que envolve a reflexão sobre as regras produzidas pelas trabalhadoras ${ }^{4}$ ("Projeto Regras de Convivência"), a sua percepção como um fenômeno de caráter jurídico não estatal e sua importância para a construção do comum a partir do trabalho associado.

Muito embora devam ser tangenciadas algumas questões teóricas sobre a caracterização de tal fenômeno normativo como jurídico - considerando que toda uma longa tradição das ciências jurídicas vai no sentido contrário - , a preocupação central da pesquisa é, sobretudo, a de identificar, a partir da práxis, as características e os sentidos que assumem, no trabalho coletivo autogestionário, as regras produzidas espontaneamente pela convivência, assim como o papel que podem representar nas desafiadoras lutas populares por modos de existência ${ }^{5}$ contrahegemônicos.Com o projeto buscamos, afinal, contribuir para a construção de espaços em que está

\footnotetext{
${ }^{3} \mathrm{O}$ duplo formalidade/informalidade assume sentidos muito mais amplos do que a mera adequação do sujeito à "forma" - isto é, às regras legais de personificação e à regularidade perante a Administração Pública. Neste sentido, um grupo formalizado juridicamente pode ser, por sua atividade e demais características, considerado como parte do "setor informal" da economia. Trata-se de categorias marcadas por intenso debate teórico, iniciado na década de 1970, com pesquisas patrocinadas pela Organização Internacional do Trabalho, sobretudo em África (Hart 1973), e se complexifica ao longo das décadas seguintes, nos embates acerca das peculiaridades do mundo do trabalho dos países do "terceiro mundo", sobretudo África e América Latina. Neste contexto também se inserem as discussões em torno da economia popular e solidária (ou simplesmente economia solidária, expressão adotada no Brasil pelas políticas públicas dos governos petistas entre 2003 e 2016). Nos últimos anos, as investidas neoliberais - ao sul e ao norte do equador -, com uma intensa precarização da classe trabalhadora, tem alterado os termos da discussão, passando-se a falar então de uma "nova informalidade", que não mais escolhe suas vítimas entre os países mais pobres. Historiando o debate e sua evolução, consulte-se Machado da Silva 2002, Peres 2017, Gago 2018.

${ }^{4}$ Utilizarei o feminino pela predominância quase absoluta das mulheres nos grupos, como adiante será esclarecido.

5 A contraposição entre "modos de existência" e "modos de produção" é feita por Mina Navarro (2013), a partir do desenvolvimento do pensamento de Massimo de Angelis.
} 
em jogo não só a reprodução da vida por meio do trabalho concreto, não alienado ${ }^{6}$, mas a produção de estratégias políticas para a participação autônoma do decidir coletivo, o respeito à opinião do outro, o aprendizado para o diálogo, a convivência sem hierarquias.

A exposição é dividia em duas partes. Na primeira, apresento a experiência: os grupos, o projeto "regras de convivência", o que fazemos juntos(as) e como fazemos. Na segunda, reflito sobre a experiência sob o prisma mais diretamente jurídico. Embora aqui - considerando o predomínio da compreensão do Direito como produção do Estado - tenha de início de sustentar teoricamente porque entendo as "regras de convivência" como Direito, a intenção principal é iniciar alguma sistematização das observações acerca de como as normas construídas no exercício de autogestão dos grupos funcionam na dinâmica de luta das trabalhadoras, nos desafios da convivência e do exercício coletivo do poder - como elas podem contribuir, afinal, para produção do comum - categoria que igualmente é mobilizada no texto.

\section{AS TRABALHADORAS E SUAS REGRAS DE CONVIVÊNCIA}

O primeiro projeto Cantina Solidária, iniciado em 2013, contou com a participação da Copermasol, grupo urbano majoritariamente feminino ${ }^{7}$. A oportunidade de ocupar o espaço de alimentação da Universidade fez o grupo crescer numericamente, reunindo pessoas que, embora se conhecessem (pela vizinhança na Queimadinha, bairro popular de Feira de Santana), nunca haviam trabalhado juntas. O processo gerou, como é de se imaginar, conflitos constantes e, por consequência, uma demanda do grupo pela “ajuda” da Incubadora na sua solução.

A minha atuação, enquanto integrante da área jurídica, foi direcionada pelo próprio grupo, então, para pensar estratégias que tornassem possível um convivência menos turbulenta: antecipando as principais zonas de conflito (em especial, divisão do trabalho e dos ganhos, entrada e saída de novas integrantes, dinâmicas de exercício do poder interno), pensando mecanismos de

\footnotetext{
${ }^{6}$ Ou do fazer, como propõe John Holloway (2013), a partir da ideia da "dupla natureza do trabalho", desenvolvida por Marx para desvendar o processo de abstração do fazer em trabalho sob o capitalismo. "O fazer concreto, então, não é totalmente subordinado ao trabalho abstrato [...]. Certamente ele existe no trabalho abstrato: o trabalho abstrato é a forma na qual o fazer concreto existe na sociedade capitalista. O fazer que está envolvido em qualquer tipo de produção é sujeitado, direta ou indiretamente, aos requisitos da produção para o mercado, os requisitos da produção de valor [...]. Mas o fazer existe também em revolta contra o trabalho abstrato: em toda recusa da autoridade alienada, em toda tentativa de ganhar controle sobre o processo de trabalho ou de desenvolver atividades significativas fora da jornada de trabalho ou como um emprego alternativo, ocasionalmente também como explosões de recursa (carnavais, motins, rebeliões)" (Holloway 2013: 168-169)

${ }^{7}$ O grupo, na verdade, começou sua relação com a IEPS em 2008, tendo sido a primeira experiência da incubação do Programa. No seu início contava com cerca de 20 pessoas, dedicando-se à produção de alimentos. A falta de um local para trabalhar, equipamentos, recursos fez o grupo minguar, até quando, em 2013, iniciou-se o Projeto Cantinas Solidárias, com a oportunidade de ocuparem a cantina do módulo VII da UEFS. No período que se inicia em 2013 (de que cuido neste texto), o grupo também variou numericamente, mas contou apenas com uma (efêmera) presença masculina.
} 
mediação destes $\operatorname{conflitos}^{8}$, propondo uma "visualização" mais sistemática das regras que elas iam criando à medida que conviviam. Foi esta a origem do que acabamos chamando, meio de improviso, de "regras de convivência".

O trabalho, assim, respondia à metodologia que guia os trabalhos da IEPS - a que temos preferido denominar de pesquisa participante ${ }^{9}-$, no sentido do compartilhar coletivo do processo de produção do conhecimento pelos(as) integrantes "acadêmicos(as)" do projeto e pelas trabalhadoras que factualmente protagonizam a realidade. É um processo certamente difícil e não é rara a sensação de insegurança da equipe - "a gente não sabe o que está fazendo", leio nos meus registros daquele tempo em uma das reuniões semanais da IEPS. A pesquisa participante caracteriza-se por um movimento contínuo e pendular do pesquisador em relação à realidade: dela se aproxima e se afasta continuamente, num processo que é comparado por René Barbier (2007) a uma espiral, onde se sucedem planejamento, ação e reflexão. Nas palavras de Fals Borda (2009: 263), "uma sequência de ritmos no tempo e no espaço que incluem aproximar-se e distanciar-se das bases, ação e reflexão".

No calor dos acontecimentos e demandas, no entanto, o tempo da reflexão tarda mais do que se gostaria e, na verdade, é em si um processo lento e descontínuo. Só agora, após várias experimentações da produção de "regras de convivência", talvez estejamos nos aproximando de uma maior clareza do processo, de seus ganhos e perdas, do papel que ele tem para as trabalhadoras e que nele assume a IEPS-UEFS.

Basicamente, o processo consistia em reuniões presenciais, com a presença de professores(as), estudantes e das trabalhadoras, em que se discutiam temas previamente sistematizados, a partir da observação do trabalho na Cantina, das demandas do grupo ("a gente está tendo dificuldade em dividir os turnos" ou "a gente precisa de ajuda para fazer as contas na hora de dividir o dinheiro"), pelas rodas de conversa realizadas em outras frentes do processo de incubação (a exemplo do acompanhamento econômico-contábil ou das boas práticas na produção de alimentos).

\footnotetext{
${ }^{8}$ O que deu origem a outro subprojeto - "Mediação de conflitos no trabalho autogestionário" - , que contou com a participação de duas estudantes do Curso de Graduação da UEFS, como bolsistas de iniciação científica. Sobre ele ver, Santos 2014, Silva 2016.

${ }^{9}$ Sem desconhecer a profusão de diferentes linhas dentro deste universo (pesquisa-ação, pesquisa militante, pesquisa luta, pesquisa-ação participativa), temos amparado nossa atuação de forma preponderante na linha teórica latinoamericana, construída sobretudo nas décadas de 1960 e 1980 no contexto de movimentos sociais emergentes que estavam inseridos em comunidades populares e de propostas de transformação social e política. A preferência explicase, primeiro, pela intenção deliberada de privilegiar a tradição latino-americana, e, sobretudo, brasileira - em que se destaca o pensamento de Paulo Freire - e pela centralidade que a educação popular ocupa nos trabalhos de incubação. A metodologia participativa, sob esse prisma, é um instrumento científico que possui dimensão tanto política quanto pedagógica, sendo mais ampla do que a própria pesquisa e preocupando-se com uma continuidade do trabalho, ou seja, com uma transformação positiva da realidade social da comunidade participante do estudo. A transformação social seria o resultado de uma equação que soma a investigação, a educação e a ação social (Brandão 2007).
} 
Porque no caso da Copermasol, desde o início, houve uma demanda também sempre presente pela "formalização" (nascida da constatação pelas trabalhadoras da falta que fazia o "CNPJ"10 para vários fins - abertura de uma conta bancária, compras mais baratas no atacado, perda de oportunidades de venda em razão da impossibilidade de emissão de notas fiscais etc.), optamos por estabelecer uma ordem nos temas que tinha uma certa homologia com as partes constituinte de um suposto "estatuto" futuro (embora não se tivesse por objetivo naquele momento a "formalização" do grupo como uma pessoa jurídica, ação que nos parecia prematura ${ }^{11}$ ). As discussões, no entanto, não eram pautadas por "o quê a Lei dizia" sobre o tema, nem por uma "forma de agir" determinada pela Incubadora. A proposta era captar a forma como elas já vinham agindo a respeito de cada tema, ou como pretendiam agir dentro de um campo que se configurava novo e como iam ajustando os diversos interesses individuais a partir da convivência.

Trazia-se à tona um processo que acontecia de maneira implícita, sem que as trabalhadoras de fato pensassem sistematicamente sobre ele. A prática de discussão coletiva, em si, era algo muito difícil para elas ${ }^{12}$, em sua maior parte sem uma história prévia de participação em espaços coletivos de decisão, prevalecendo experiências de trabalho subordinado ou do trabalho doméstico de cuidados da casa e dos filhos. A proposta era, então, estimular as trabalhadoras a falar sobre como agiam em grupo ao trabalhar juntas. Professores(as) e estudantes participavam das reuniões, questionando sobre diferentes aspectos, contribuindo com propostas de organização, relatando sobre outras experiências de trabalho coletivo. A equipe da IEPS também responsabilizava-se por transformar as regras orais em um texto escrito, que afinal tomou o mesmo nome criado durante o processo: "Regras de Convivência da Copermasol"13. Transcrevo abaixo algumas regras que o compõem, retiradas aleatoriamente do documento (dividido em três partes: "a divisão do trabalho"; "a divisão dos ganhos"; "a resolução de conflitos"):

Todos devem aprender a realizar todas as tarefas da cantina, e estar disponíveis para realizá-las. O trabalho será dividido por turnos de 6 horas, cujos horários de início e fim

\footnotetext{
${ }^{10}$ Muito embora, segundo a Lei Civil brasileira, a pessoa jurídica "exista” para o Direito já a partir de sua "inscrição do ato constitutivo no respectivo registro", o processo de formalização somente se completa, verdadeiramente, com um novo processo de "inscrição", desta feita perante o chamado Cadastro Nacional de Pessoas Jurídicas, banco de dados administrado pela Receita Federal que compreende as informações cadastrais das administrações tributárias da União, dos Estados, do Distrito Federal e dos Municípios. Enquanto o grupo não detém o seu "CNPJ”, mesmo já personificado como uma cooperativa, uma associação ou outro qualquer tipo de pessoa jurídica, o processo de formalização não atinge, de fato, o seu objetivo: isto é, tornar possível ao grupo, sob os olhos do Estado, produzir rendimentos para seus componentes atendendo as exigências estatais, especialmente as tributárias.

${ }^{11}$ Discuto a questão da formalização jurídica de grupos de trabalho associado no Brasil em Pita 2017 (texto em espanhol) e 2018 (texto em português).

12 A partir desta constatação realizamos uma "oficina" sobre "como fazer uma reunião" - discutindo-se como escolher os temas que seriam discutidos, como organizar as falas, como decidir, como registrar as decisões, como guardar os registros.

${ }^{13}$ No caso da Copermasol, este documento escrito serviu de base para um contrato social, organizado nos moldes da Lei Civil brasileira, que deu origem a uma pessoa jurídica, estruturada sob a forma de "sociedade simples". Tratamos desta experiência em Oliveira, Pita 2017.
} 
serão determinados de acordo com a demanda de trabalho na cantina. Todos deverão zelar pelo cumprimento dos horários, justificando com antecedência uma eventual falta ou atraso, de modo que o grupo possa se organizar a tempo de substituir a pessoa ausente e não prejudicar o andamento dos trabalhos. As compras serão atribuição de uma equipe, formada por um membro de cada turno. O grupo deve priorizar a solução dos problemas através do diálogo e do acordo.

Em 2014, muito em razão da bem sucedida experiência com a Copermasol ${ }^{14}$, a Administração Universitária concedeu à IEPS, para os mesmos fins, o espaço de uma outra cantina no campus (são quatro no total). Após processo seletivo simplificado, realizado durante o segundo semestre de 2014, inicia-se em 2015 o Projeto Cantina Solidária II com o grupo Sabores, também preponderantemente feminino e urbano. Esse segundo Projeto, com duração originariamente prevista para dois anos, foi prematuramente extinto no final de 2016. As observações feitas pela equipe da IEPS apontavam para o mascaramento de relações de trabalho subordinado, em torno da "líder" do grupo (constatou-se, ao longo do processo, que o grupo reproduziu, na cantina da UEFS, relações de trabalho subordinado que já aconteciam anteriormente entre as mesmas pessoas). Havia, também, muita resistência à participação nas atividades propostas pela Incubadora e o grupo não demonstrou interesse em repetir a experiência das "regras de convivência" - as regras pareciam préestabelecidas, e fora de discussão; as reuniões aconteciam preenchidas de silêncio da maior parte do grupo, em contraste com a participação da sua "líder". Apesar da frustração inicial da equipe da IEPS com o processo, a experiência revelou-se bastante rica para refletir sobre as contradições e obstáculos que enfrenta a construção de um espaço de trabalho autogestionário e sobre a nossa metodologia de atuação.

O Projeto iniciou sua terceira versão ainda em 2016, desta feita com um grupo rural, o Sabores do Quilombo, também preponderantemente feminino, proveniente de uma comunidade quilombola do município de Feira de Santana (Lagoa Grande). O Sabores do Quilombo tem proporcionado uma nova e rica experiência coletiva de construção de "regras de convivência". Também aqui a demanda do grupo, no sentido da "ajuda" da Incubadora para enfrentar as dificuldades da convivência apareceu cedo (e permanece presente até o momento) e nos fez constatar o caráter "artesanal" do processo: embora em linhas gerais tenha se mantido a metodologia de reuniões periódicas e a proposta de temas de discussão, o novo grupo exigiu da IEPS diferentes reflexões e abordagens. Se a perspectiva inicial - contribuir com o processo de criação das regras que o coletivo de trabalho produzia no processo de sua instituição - já havia se alargado pela realidade, que exigira reflexões sobre a condição feminina, a família, o trabalho

\footnotetext{
${ }^{14}$ A equipe da IEPS chegou a realizar, em 2014, pesquisa com os usuários da cantina, como parte integrante do relatório final apresentado à Universidade. Os dados levantados (por meio da aplicação de 80 questionários) indicavam a aprovação do grupo pela comunidade universitária em aspectos como a qualidade do alimento produzido e atendimento, e mesmo a preferência em relação às demais cantinas da universidade.
} 
informal, os obstáculos do meio urbano, as barreiras à comunicação oral e escrita para as classes populares, o novo projeto colocava (ainda mais) luzes sobre a questão racial (e, junto a ela, sobre os modos de viver quilombola e rural).

Destaco duas características divergentes deste projeto em relação aos anteriores. A primeira diz respeito à ausência, até o momento, da elaboração de um documento escrito que sistematize as regras discutidas. A conveniência da tradução das regras para a linguagem escrita é uma questão aberta para nós, a exigir reflexão. A segunda característica é o elastecimento temporal do processo, que iniciou em 2016 e permanece sendo uma demanda das trabalhadoras. Em reunião, realizada no final de 2018, com o objetivo de avaliar o ano de trabalho e recolher elementos para o planejamento da próxima etapa, as trabalhadoras, ainda às voltas com dificuldades de relacionamento e desconfianças mútuas, elegeram "as regras de convivência" entre os temas que desejavam fosse objeto das atividades com a Incubadora. As regras que conformam um coletivo baseado na autogestão podem realmente ser tidas como "prontas" em um dado momento? A sua reificação como "algo" acabado é possível? É desejável? Quais são seus efeitos sobre o grupo? Ou o que representaria, por outro lado, pensar a produção das regras coletivas como um processo contínuo, que exige sempre rediscussão, renovação? Tratarei destas questões na última parte do texto.

Finalmente, em 2017, inicia-se o Projeto Cantina Solidária IV, selecionando-se um grupo rural da comunidade de Olhos D’Água da Formiga, zona rural de Feira de Santana, para ocupar o espaço da cantina VII. O Delícias da Formiga parte de uma experiência de trabalho coletivo em uma associação juridicamente formalizada (embora o grupo produtivo da cantina não seja, em si, uma associação, mas um grupo informal). A Associação Comunitária de Olhos D’Água da Formiga contava com um grupo produtivo de mulheres, envolvido na produção de alimentos (especialmente sequilhos) para comercialização no Programa Nacional de Alimentação Escolar-PNAE ${ }^{15}$.

Nos primeiros meses do processo de Incubação definiu-se o grupo de mulheres interessadas em participar da experiência com a IEPS e iniciaram-se uma série de atividades que envolveram a aproximação com os princípios do trabalho autogestionário e da economia popular e solidária. O que se viu, no entanto, depois de algum tempo, foi uma crescente animosidade entre as trabalhadoras e a presidente da Associação, que também integrava o grupo da cantina. Uma das estratégias utilizadas pela IEPS para contornar os problemas foi, justamente, o anúncio do início do processo de construção das regras de convivência.

\footnotetext{
${ }^{15}$ A Lei Federal n. 11.947, de 16.06.2009, determina que 30\% do valor repassado pelo governo federal pelo Programa Nacional de Alimentação Escolar - PNAE seja destinado à compra direta de produtos da agricultura familiar.
} 
Figura 1: Slide utilizado em roda de conversa, ocorrida em 31.01.2018, para planejamento do projeto "regras de convivência" com o grupo Delícias da Formiga

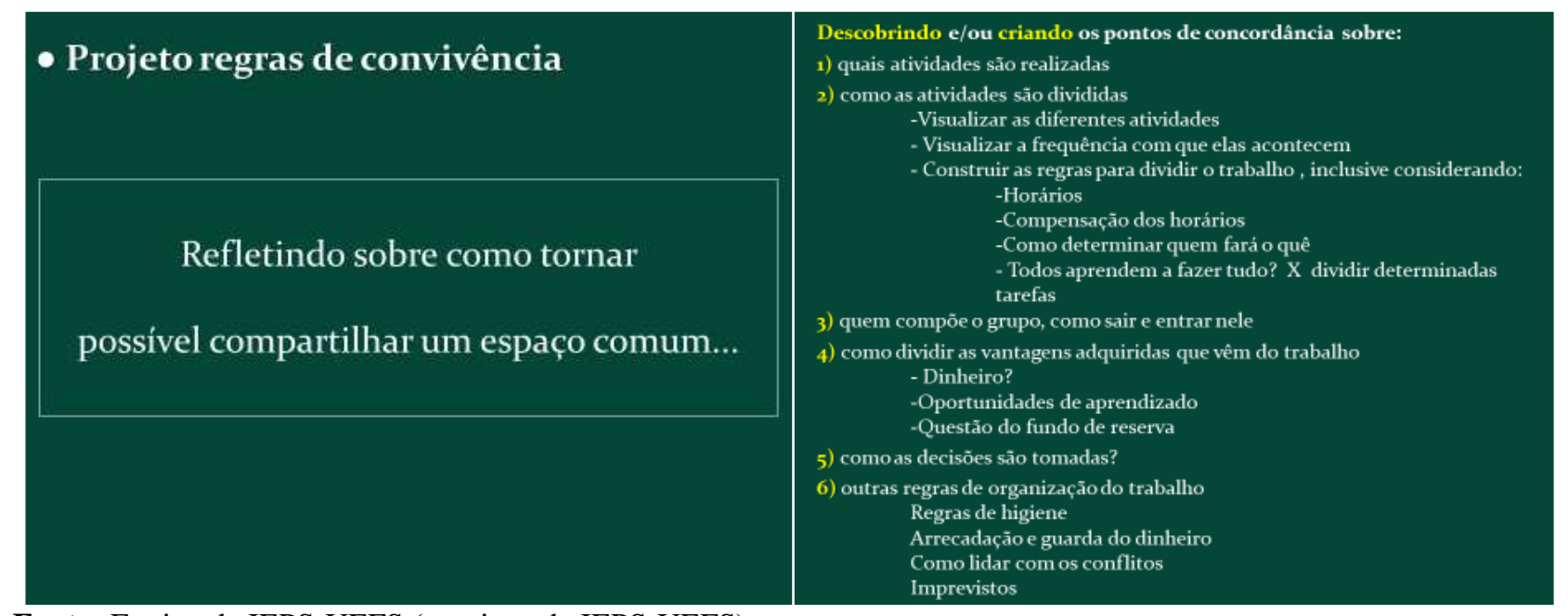

Fonte: Equipe da IEPS-UEFS (arquivos da IEPS-UEFS)

Se, por um lado, a líder do grupo anunciava que "se eu sair o grupo acaba, elas não têm condição de continuar sem mim", a pauta de questões como a transparência e participação nas decisões sobre a movimentação e divisão do dinheiro do grupo, ou sobre como se dava a divisão do trabalho entre as trabalhadoras (a líder exercia um papel de chefia, sem se envolver, por exemplo, com os trabalhos de preparação dos alimentos) parece ter contribuído para o enfrentamento das demais componentes à autoridade construída por ela ao longo do tempo. Esta primeira fase do processo acabou por resultar na saída da presidente do grupo da cantina, que foi seguida por outras duas pessoas. As demais resolveram prosseguir no projeto, convidando outras mulheres da Associação. As trabalhadoras desde então permanecem desenvolvendo juntas um trabalho muito elogiado na Universidade. Uma delas recentemente nos indicou a vontade de concorrer à presidência da Associação, no pleito que ocorrerá em meados de 2019.

Por fim, menciono brevemente o projeto "Feira de Saberes e Sabores", por meio do qual a IEPS-UEFS vem realizando uma feira de economia popular e solidária no campus da UEFS. A Feira corresponde igualmente a um coletivo autogestionário formado pelos(as) feirantes, entre os(as) quais estão as trabalhadoras do Sabores do Quilombo e do Delícias da Formiga, além de agricultores(as) das respectivas comunidades - com o que se estabelece um elo com o Projeto Cantinas. Também a Feira tem suas "regras de convivência", construídas a partir da mesma metodologia. Neste caso, considerando a rotatividade dos(as) componentes, e da possibilidade aberta à inscrição e admissão de novos(as) integrantes, a elaboração de um documento escrito - e publicizável - foi um objetivo inicial, já que era importante para o projeto dar transparência ao 
processo. Neste caso, as regras podem ser consultadas em sua íntegra na página da IEPS-UEFS na internet $^{16}$.

\section{AS REGRAS DE CONVIVÊNCIA COMO DIREITO DO COMUM}

Num primeiro momento, pensar as "regras de convivência" como Direito demanda um posicionamento sobre a discussão teórica acerca do próprio conceito de Direito. Ela se conecta, por sua vez, com a forma como a teoria crítica ${ }^{17}$ se aproxima desta questão: por um lado, o vaticínio do "fim do Direito" como produto do fim do capitalismo, por outro, o multifacetado tema do pluralismo jurídico. Alerto que, embora esta questão seja tratada em primeiro lugar nesta exposição, isto se dá em função da lógica do raciocínio desenvolvido: a práxis não a exigiu como prioridade e dela cuidarei de maneira breve.

Em segundo lugar - sendo este o prisma que se tem por central no projeto - a preocupação de pensar o processo de construção de regras a partir de sua práxis mesma (para o que é irrelevante saber se elas recebem, ou não, o selo de "jurídicas"), identificando suas características e sua importância para o trabalho coletivo autogestionário, para a construção do comum. Para pensar como este processo pode ser mais ou menos proveitoso para o grupo, e como pode ser mais ou menos útil a nossa participação, enquanto acadêmicos(as) (do Direito, inclusive), na organização comunitária de formas de trabalhar que visam a superar o capitalismo.

\subsection{As regras de convivência são direito?}

A história do processo de predomínio do capitalismo e do trabalho abstrato é marcada pela crescente autonomização das esferas da economia, da política, do Estado e de seu Direito em relação a outras dimensões do social (Holloway 2013: 107-157). A palavra Direito passa paulatinamente a denominar, em uma construção simbólica que se inicia já no século XV, uma dimensão do social que se vincula ao Estado e se distingue de outros conjuntos normativos (como a moral, a religião, as normas técnicas das profissões) por algumas características centrais: i) o Direito é um só (monismo jurídico), formando um todo racional e sistemático desenvolvido a partir da ideia do direito de propriedade, que adquire sua "positividade" pelas mãos do Estado (fonte única de sua produção e aplicação); ii) ele deixa de ser algo produzido pelas relações humanas em diferentes agrupamentos (e marcado por isso pela multiplicidade - direito romano, canônico, comum, feudal, dos comerciantes, da comunidade) - para assumir o caráter de um "produto" da

\footnotetext{
${ }^{16}$ Acessível em https://incubadorauefs.blogspot.com/p/a-feira-de-saberes-e-sabores.html

${ }^{17}$ Entendida aqui como o campo teórico do marxismo, no sentido consagrado por Horkheimer (1983). 
razão, universal e sem história; c) a estatalidade e o monismo do Direito tornam fundamental a distinção do Direito de outros conjuntos normativos (em especial, a moral), para o que de regra são mobilizadas as características da heteronomia (o Direito se impõe sempre por força de uma terceira vontade - o Estado -, de fora para dentro, sobre as relações afetadas por suas regras), da bilateralidade (presença necessária da dualidade credor/devedor) e, por fim, da sanção "organizada", ou "institucionalizada" (por meio da qual se relembra, mais uma vez, o papel do Estado como sancionador privilegiado $)^{18}$.

"Vossas próprias ideias são produtos das relações de produção e de propriedade burguesas, assim como o vosso direito não passa da vontade de vossa classe erigida em lei, cujo conteúdo é determinado pelas condições materiais de vossa existência como classe" - seria "àquele" Direito, delineado pelo capitalismo, que se referiam Marx e Engels no Manifesto ${ }^{19}$ ? (2007: 55). Ou, como anunciava o jurista soviético Pachukanis, “a extinção das categorias do direito burguês [...] significará a extinção do direito em geral, ou seja, o desaparecimento gradual do momento jurídico nas relações humanas"? (2017 p. 78). Na tradição dos estudos marxistas do Direito são conhecidas as discussões em torno da relação supostamente necessária entre a "forma jurídica" e o modo de produção capitalista. A superação do capitalismo implicaria o fim o direito? Reproduzindo as desavenças do debate soviético entre Stucka e Pachukanis ${ }^{20}$, a discussão estende-se ao Direito crítico contemporâneo e à produção brasileira ${ }^{21}$.

Embora não tenha como aqui enveredar por essa longa e conflituosa discussão, parto da compreensão de que a convivência nos grupos de trabalho autogestionário submete-se a uma lógica própria, que envolve uma regulação jurídica muito peculiar. Isto porque tal ordem normativa, mesmo que estranha ao Estado e carente de um órgão sancionador, compartilha com o que conhecemos por "Direito" o fato de representar, para aquelas trabalhadoras, a "liga" que faz do

\footnotetext{
18 Roberto Lyra Filho (1982) (1986) e Luiz Fernando Coelho (1987) desenvolvem mais a fundo estas ideias, demonstrando também o quanto estas características são insuficientes para distinguir as normas jurídicas das demais.

${ }^{19}$ Roberto Lyra Filho faz uma síntese dos obstáculos que tornam a tarefa de falar sobre Marx e o Direito um "vespeiro ameaçador e fervente" (1983: 10). Chama de "lógico"(1983: 13) o que derivaria da inconclusa sistematização do método dialético pelo próprio Marx. Salienta também a ausência mesma de um tratamento teórico específico por Marx sobre o Direito (1983: 22). Lyra Filho também retoma o problema cronológico, apontando (e criticando) a conhecida periodicização do "jovem" e o "velho" Marx, a dificultar a leitura processual e integral do pensador alemão (1983: 29) e menciona um obstáculo "psicológico" (1983: 40), onde salienta a desilusão e rompimento de Marx com sua carreira jurídica como elemento que deve ser aquilatado na interpretação de seus posicionamentos sobre o Direito.

${ }^{20}$ Lembro aqui a ótima retrospectiva que dele faz Ricardo Prestes Pazello (2014, pp. 262-322).

${ }^{21}$ Destaco nela os seguintes nomes: de Roberto Lyra Filho e seu "Direito achado na Rua" (cuja tradição é levada adiante especialmente pela produção que vem da Universidade de Brasília-UnB, com José Geraldo da Sousa Júnior); Luis Alberto Warat, cuja singularidade de pensamento me faz preferir não vinculá-lo a um grupo específico; o movimento do Direito Alternativo (de Rui Portanova, Amilton Bueno de Carvalho e Edmundo Lima Arruda Júnior, entre outros); o Pluralismo Jurídico de Antônio Carlos Wolkmer e do português Boaventura de Souza Santos (incluído entre os brasileiros em razão da conhecida e influente pesquisa realizada em uma favela carioca); o movimento do Direito Insurgente, gestado a partir da produção do Instituto Apoio Jurídico Popular - AJUP, no Rio de Janeiro, pela tradição da assessoria jurídica popular de Miguel Pressburger, Miguel Baldez e Jacques Alfonsin; e, por fim, a produção da escola paulista formada em torno, especialmente, de Alysson Mascaro e Márcio Bilharinho Naves.
} 
grupo um espaço comum de produção, decisão e execução de ideias e ações coletivas, instância de formulação de sua autonomia identitária e política. A intenção não é, porém, capturar o Direito em um conceito sem lugar e tempo, mas exercitar uma ontologia histórico-dependente, em que se enrijece os elementos da realidade apenas o suficiente para garantir a reflexão transformadora neste caso, para fundamentar a conclusão de que, tanto quanto a Lei produzida pelo Estado, são Direito as regras produzidas pelas trabalhadoras em seu convívio ${ }^{22}$.

Em sua tentativa de definição do Direito, Michel Miaille entende-o como um "sistema de comunicação formulado em termos de normas para permitir a realização de um sistema determinado de produção e de trocas econômicas e sociais" (Miaille 2005: p. 96). Gosto da definição de Miaille em especial pelo recurso à ideia de um "sistema de comunicação". Isto, em primeiro lugar, afasta o senso comum de valorizar a norma, ou mais especificamente, a Lei, para a caracterização do Direito. Neste sistema integram-se tanto valores (isto é, indicativos normativos de como deve ser o comportamento humano) quanto instituições e processos, práticas, modos de agir e de se relacionar que assume a agência humana em comunicação. Em segundo lugar, gosto dela por lembrar que o Direito é, sobretudo, comunicação: "não é sólido, nem líquido, nem gasoso", como costumava dizer o jurista baiano José Joaquim Calmon de Passos:

Onde situar o Direito, objeto de nosso interesse no momento? [...]

Situa-se, pois, no universo do discurso e da ação, somente existindo enquanto discurso e comunicação, linguagem, processo, fazer operar. Ontologicamente (diria melhor, onticamente) portanto, nada é jurídico ou antijurídico, lícito ou ilícito na conduta humana. O jurídico é sentido e significação, que os homens emprestam a determinados atos seus, para ter atendida certa imprescindível e específica necessidade de convivência social. (PASSOS, 1999, p. 22).

A definição de Miaille e o pensamento de Calmon de Passos abrem-se para a possibilidade de um outro Direito. Ora, se compreendo o Direito como um "sistema de comunicação" que ampara um determinado "sistema de produção e de trocas econômicas e sociais", outros sistemas de produção de trocas econômicas e sociais gestaram e gestarão “outros Direitos”. Copermasol, Sabores do Quilombo e Delícias da Formiga, em suas diferentes maneiras de negar o absoluto do capital, distinguindo-se do modo capitalista de trabalhar (mesmo considerando as limitações impostas pelo entorno hegemônico do valor ${ }^{23}$ ) produzem microssistemas de produção da existência que exigem um sistema normativo peculiar de comunicação.

\footnotetext{
${ }^{22}$ Talvez uma tarefa importante da crítica acadêmica seja a nomeação deste outro Direito, um batismo que fuja ao simples acréscimo de adjetivos (Direito "alternativo", Direito "achado na rua", Direito "insurgente”). Resgatar um signo do vocabulário dos espaços em que este outro Direito sempre se produziu e fazê-lo eloquente além dele. Ainda não o encontramos, mas este parece ser um bom exemplo do papel que pode assumir a academia nas lutas populares.

${ }^{23}$ Parecem oportunas aqui as categorias marxianas da subsunção formal e material do trabalho (Marx 1978), na forma como retomadas por Lucia Insalata (2011). Estamos diante de espaços em que a subsunção do trabalho à lógica do capital é tão somente formal - "porque se trata de realidades sociales que, a pesar de ser subordinadas y, de alguna $u$ otra forma, condicionadas por la lógica reproductiva del capital, logran preservar un margen de autonomía más o
} 
Atribuir o signo do jurídico ao sistema normativo dos grupos de trabalho autogestionário assume, ainda, uma intencionalidade política específica. Na mesma medida que o monismo jurídico estatal possui simbolicamente um sentido estratégico de dominação, a sua negação reveste-se de insubordinação. Reconhecer a possibilidade da simultaneidade de outros Direitos é dar afirmatividade à luta contra a redução da sociedade à sociedade burguesa. É só a esta, afinal, que o Direito estatal acolhe - se o Direito das constituições e leis assume aparentemente como valores um discurso de "igualdade" e "justiça", isto é negado em suas instituições e processos, já que a linguagem dos textos legais e das audiências, os espaços físicos, os custos, a cor da pele, o predomínio da linguagem escrita, a lógica binário do perder/ganhar, tudo fecha as portas do Direito estatal para a porção que vive no espaço da negação do mundo capitalista (não ocidental, nãobranca, não-masculina, não-urbana...).

\subsection{As Regras de convivência como Direito do Comum}

O “comum” é uma categoria que vem sendo tecida já há algumas décadas e parece assumir aquele mesmo caráter afirmativo: nomeia-se, afirma-se uma práxis que se posiciona em enfrentamento ao modo predominante de viver, trabalhar, se relacionar, lutar, gestionar o poder no mundo capitalista. Ela vem sendo utilizada por nós na IEPS-UEFS para compreender e falar do trabalho coletivo autogestionário e para adjetivar este outro Direito que é produzido pelas trabalhadoras.

A disseminação acadêmica da categoria do comum tem uma história relativamente recente e vertentes diversas. Muito embora o sentido de um espaço político de negação da apropriação privada de bens e de comunhão horizontal de exercício do poder encontre raízes em doutrinas religiosas no ocidente e oriente, no modo de vida de populações originárias das Américas e da África, nos soviets russos, no pensamento comunista e anarquista ${ }^{24}$, a disseminação do uso acadêmico e político da palavra (no plural ou no singular) é contemporânea dos movimentos

menos amplio en los procesos de significación, articulación y organización de la vida que se desarrollan en ellas (2011: 37-8). É certo, no entanto, que mesmo aí não se está absolutamente afirmando a "desaparición de la explotación y del despojo capitalista o de la ausencia de formas de control político y disciplinario sobre la realidad en cuestión" (2011: 39). Tais brechas na subsunção real do trabalho, mesmo que ambivalentes, expõem as debilidades do capitalismo, e iluminam espaços de resistência, de luta, de superação.

${ }^{24}$ Os franceses Pierre Dardot e Christian Laval (2017) remontam a diferentes modelos de comunismo, como a concepção que "se prendeu ao valor supremo da comunidade" - a concepção de "comunidade de vida" presente n'A República de Platão, ou a tradição judaico-cristã da "comunidade de bens", elemento igualmente presente nos movimentos heréticos (taboristas, hussitas, valdenses, cátaros, bogomilos diggers) que representaram uma longa tradição de lutas durante o feudalismo e nos momentos iniciais do capitalismo. Em seguida, retomam a tradição do socialismo europeu - o "comunismo da associação dos produtores" que passa tanto pelo socialismo "utópico" (SaintSimon, Fourier, Proudhon, Owen etc.) quanto pelo concepção marxista de comunismo. 
altermundistas do final do século XX, que disseminaram a metáfora do "cercamento dos comuns" 25 para apontar a permanência dos movimentos expropriatórios (dos recursos naturais, dos serviços públicos, das garantias coletivas conquistadas nos Estados de bem-estar social, dos corpos e desejos dos(as) trabalhadores(as), mulheres ${ }^{26}$, não-brancos(as) que desvelam a acumulação dita "primitiva" como uma presença necessária e constante para a permanência do capitalismo.

Pierre Dardot e Christian Laval, identificando o comum como "o princípio das lutas atuais contra o capitalismo" (2017: 24) e propondo-se a fazer sua arqueologia, citam os trabalhados de economia política institucional de Elinor Ostrom e demais pesquisadores estadunidenses, a partir do debate iniciado com "The Tragedy of the Commons" de Garrett Hardin (1968). Laval e Dardot atribuem a Ostrom um lugar de destaque no surgimento do "paradigma dos comuns", na medida em que, voltando-se seus olhos para o modo como as experiências reais de comum são instituídas enquanto modo específico de gestão de atividades e coisas, "ela realiza um deslocamento decisivo, situando a questão do comum no campo da ação coletiva e de suas condições políticas" (2017: 197198). Os franceses dedicam-se sobretudo, no entanto, ao pensamento Michael Hardt e Antonio Negri, a quem tributam “a introdução da categoria 'comum' (no singular) no pensamento político crítico e sua difusão entre o público militante” (2017: 199). Em sua conhecida trilogia (Multidão, Império e Commonwealth ${ }^{27}$ ), Hardt e Negri acreditam que "a produção capitalista contemporânea, ao atender a suas próprias necessidades, possibilita e cria as bases de uma ordem social e econômica alicerçada no comum (2016: 10). Os próprios Dardot e Laval, finalmente, partem dos filósofos italianos (valendo-se também de variada gama de referências teóricas, que vão dos diálogos entre Proudhon e Marx aos vieses institucionalistas de Mauss, Cornelius Castoriadis e Sartre, em sua Crítica à Razão Dialética) para propor a categoria de práxis instituinte e uma série de proposições políticas cujo âmago é a proposta de uma "política do comum" - do qual resulta, igualmente, um "direito do comum": "a práxis instituinte produz seu próprio sujeito na continuidade de um exercício que deve se renovar para além do ato criador, [...] ela é autoprodução de um sujeito coletivo na e pela coprodução continuada de regras de direito" (2017: 472).

A proposta de uma práxis instituinte do comum é significativa para pensar a experiência das "regras de convivência" do trabalho autogestionário. No entanto, apesar da consistente empreitada teórica e da ousadia do formato propositivo, Dardot e Laval parecem pecar pela "hybris do ponto zero" de que fala Santiago Castro-Gómez $(2005)^{28}$ : não entendemos possível traçar uma

\footnotetext{
${ }^{25}$ No sentido explorado por Marx no famoso capítulo 24 do volume I d'O Capital, em que reconstrói historicamente a “Assim chamada acumulação primitiva" (2017 : 785-833).

${ }^{26}$ Como o demonstra Silvia Federici 2017.

${ }^{27} \mathrm{Na}$ edição brasileira traduzido como "Bem Estar Comum" (2016)

28“[...] una de las consecuencias de la hybris del punto cero es la invisibilización del lugar particular de enunciación para convertirlo en un lugar sin lugar, en un universal. Esta tendencia a convertir una historia local en diseño global,
} 
história fidedigna do comum sem um descentramento do olhar da Europa em direção ao sul global. À exceção de rápidas menções à Guerra da Água cochabambina ou às experiências das fábricas recuperadas argentinas, os franceses não chegam a explorar as ricas lutas e reflexões produzidas fora da Europa. O predomínio da abstração em detrimento da reflexão a partir das lutas e experiências concretas desde abajo dá-lhes um tom etéreo e estrutural, minando, a nosso ver, o pretendido potencial político de suas ideias. Os Autores não chegam, por exemplo, a tratar - mesmo que abstratamente - das contradições enfrentadas pela práxis instituinte do comum diante da carência de condições materiais para a autonomia - questão das mais essenciais para a realidade das lutas de maior parte dos(as) trabalhadores, em especial ao sul do Equador. Tais lacunas

[...] aleja la discusión política de su carácter concreto para reinstalarla en los nebulosos terrenos de la coherencia abstracta. En este sentido, desde una política desde la autonomía no se trata de prescribir aquello que «debe» hacerse en general, sino de reflexionar en profundidad sobre las dificultades eminentemente prácticas del camino a recorrer para construirlo que en común se proyecta y de encontrar cada vez, procurando no perderse, maneras de sortear obstáculos” (Gutiérrez 2017: 63).

Para a realidade que vivenciamos em nossas pesquisas é muito eloquente a versão que o comum assume no pensamento coletivo do Entramados Comunitarios $^{29}$, seminário permanente do programa de pós-graduação em Sociologia da Universidade Autônoma de Puebla (México): um horizonte comunitário-popular reconhecível nas lutas latino-americanas que se opõem à expropriação capitalista da forma popular (e sobretudo feminina) de reprodução da existência. Lucia Linsalata e Huáscar Salazar reforçam a função pragmática e transformadora do conceito:

Preguntarse el “ppara qué?” de lo común significa, para nosotrxs, reflexionar sobre las múltiples relaciones de cooperación que hombres y mujeres tejemos cotidianamente, en diferentes lugares del mundo, para reproducir nuestra vida de forma satisfactoria; reflexionar sobre las formas históricas de estas relaciones, sus razones, sus potencias, sus límites, sus fragilidades, sus futuros. Significa reflexionar sobre las posibilidades de emancipación social anidadas en el hacer cotidiano de mujeres y hombres que, desde distintas latitudes del planeta, están luchando para conservar, cuidar, amplificar o reapropiarse de las condiciones materiales y simbólicas necesarias para garantizar la reproducción digna de sus vidas. Significa volver a centrar la mirada en las variopintas y coloridas tramas asociativas a lo largo de las cuales hombres y mujeres entrelazamos nuestros haceres de forma autónoma, recuperando - por lo menos en parte - la capacidad de establecer los sentidos, los ritmos y los causes de nuestra vida práctica. Finalmente,

corre paralela al establecimiento de ese lugar particular como centro de poder geopolítico. A la centralidad de España, luego de Francia, Holanda, Inglaterra y los Estados Unidos en el sistema-mundo , corresponde la pretensión de convertir su propia historia local en lugar único y universal de enunciación y de producción de co-nocimientos. [...]. La historia del conocimiento, tal como es representada desde el punto cero, tiene un lugar en el mapa, una geografía específica. Asia, África y América Latina, al igual que en el mapa T-O de Isidoro de Sevilla, quedan por fuera de esta cartografía y no son vistas como regiones productoras sino consumidoras del conocimiento generado en los centros"(Castro-Gómez2005: 61).

${ }^{29}$ Sugere-se consultar: https://horizontescomunitarios.wordpress.com/. Um rico panorama da produção do Entramados e de nomes fundamentais do pensamento latino-americano sobre o tema (destaco Raquel Gutiérrez Aguilar, Mina Lorena Navarro e Lucia Linsalata, pelo Entramados; Gladys Tzul Tzul, Silvia Rivera Cusicanqui, Luis Tapia, Raúl Zibechi, entre outros) está disponível também no número 1 de El Apantle: Revista de Estudios Comunitários (2015), no dossiê Común, ¿para qué?. 
preguntarse el “¿para qué?” de lo común significa, para nosotrxs, preguntar por los caminos de la autonomía y la audeterminación (2015: 10).

Pode-se, com Dardot e Laval (2017), reconhecer as "regras de convivência" como o Direito de uma práxis instituinte do comum. No entanto, é em busca da potência do comum/comunitário enquanto espaço de luta pela reapropriação da vida e do fazer (Holloway 2013) que se tem pensado nelas. Reconhecê-las como normas jurídicas assume um sentido para esta luta porque explicita a potência política do comum - não se trata apenas de assumir de si para si um compromisso moral com as companheiras de trabalho, nem de criar regras "técnicas" de gestão da produção para garantir sua "rentabilidade", mas de se reapropriar do poder de estabelecer as regras que tornam possível o espaço coletivo, de discutir sobre os desencontros e produzir o encontro das vontades, de exercitar a assembleia, de valorizar o que há de comum em detrimento da diferença. De fazer, afinal, ao menos na extensão possível do dia-a-dia de reprodução da vida, o que o modo capitalista expropriou em favor da abstração que é o Estado e o "seu" Direito. A aposta é que este exercício tenha a potência de contaminar outras esferas do político e estender-se e generalizar para as outras lutas.

\subsection{As regras de convivência na prática dos grupos de trabalho autogestionário do projeto cantinas solidárias}

Partindo, portanto, da ideia de que são jurídicas as regras produzidas pelas trabalhadoras no espaço coletivo e autogestionário de trabalho, e que elas fazem parte do processo de elaboração do comum, quero, finalmente, sistematizar algumas observações sinalizadas pelas experiências com as trabalhadoras. Advirto que as conclusões a que chegamos, contudo, não têm a pretensão de se reificar em regras autônomas à realidade: elas servem como inspiração para novas lutas, possibilitam a reflexão a partir da comparação, fazem pensar nos obstáculos que são comuns, sempre considerando o caráter artesanal de cada processo.

Pessoas que se reúnem para exercer uma atividade comum pactuam entre si regras, implícita ou explicitamente. Percebemos os encontros e desencontros, estratégias, sentimentos e recursos simbólicos que compartilham as trabalhadoras nos seus coletivos de trabalho como parte, assim, de um processo de instituição do comum, já que todo o movimento coletivo (compartilhado entre a equipe da IEPS e as iniciativas) se volta para o esforço de dividir espaço, tempo, bens, propósitos e afetos, com a participação genuína de todas nas decisões e atividades do grupo.

Não se trata de um movimento que se dá de forma "natural" - ele é assumido, de fato, como um esforço, uma reação a práticas contrárias e que estão inscritas na história, nos corpos, nas subjetividades de todas(os) nós, trabalhadoras(es) e pesquisadoras(es). O projeto "regras de 
convivência" foi pensado a partir deste contexto, partindo-se da hipótese de que a reflexão coletiva sobre as regras que são o amálgama de cada grupo autogestionário poderia encorpar este (difícil) acontecer contra-hegemônico.

O conflito assume um lugar importante e ambíguo no cotidiano do trabalho coletivo autogestionário. Por um lado, ele tem se apresentado em nossa experiência, ao contrário que se supõe à primeira vista, como um elemento favorável: mais conflito é sinal de mais autonomia. A apatia e aparente concordância reinante entre as participantes do grupo Sabores - que, como indiquei, estabeleceram uma clara relação de subordinação a uma das trabalhadoras - acabou por negar a presença de elementos de autogestão. Ao contrário, à medida que as trabalhadoras mostram "acreditar" que ali se pode fazer "diferente", no sentido de construírem espaços de autonomia, a tendência é o recrudescimento dos conflitos. Foi o que entendemos tenha acontecido, por exemplo, com o Delícias da Formiga, em um crescendo de desentendimentos (com um episódio, inclusive, em que se chegou à agressão física) que resultou na saída da participante que tentava exercer uma posição de hierarquia e comando no grupo.

Por outro lado, "brigar", "discutir", "agredir", "desconhecer” corroem a experiência da convivência: de forma ambígua e complexa, o mesmo conflito que sinaliza a autonomia contribui para enfraquecimento de aspectos como confiança, respeito, afeto, solidariedade, prazer em compartir e conviver.

As regras do grupo vão sendo produzidas com a convivência, com a prática do trabalho, sem que ocorra necessariamente a sua explicitação por palavras. O exercício de trazer à tona este processo, falar sobre ele, reconhecer as regras produzidas coletivamente e avaliá-las tem assumido, na nossa experiência, um papel construtivo no processo de elaboração dos laços que fazem o grupo "valer à pena".

No processo de acompanhamento das discussões dos diferentes grupos, temos identificado dois tipos diferentes de regras. Chamo de "ordinárias" as que disciplinam aspectos cotidianos do trabalho (como a divisão de tarefas, tempo de trabalho, divisão dos ganhos, por exemplo). Elas são mais afetadas pelos ritmos naturais da vida - como os diferentes ritmos de trabalho de cada pessoa, o atraso ou o afastamento que resultam de um filho doente ou de um compromisso externo, a necessidade de cobrir gastos extraordinários. Por isso, a "justiça” ou "injustiça" dessas normas, depende de um olhar mais circunstancial, tem um padrão especialmente móvel. Assim, quanto mais maleáveis, as regras ordinárias parecem melhor cumprir o seu papel. Supomos que, por este mesmo motivo, estas regras geralmente permanecem implícitas ou, no máximo, elas são enunciadas apenas oralmente. 
Já o que chamo de regras "extraordinárias" dizem respeito a aspectos mais perenes da organização do grupo ou acontecimentos que não são corriqueiros: aspectos de sua identidade (nome do grupo) e funcionamento geral (como a dinâmica dos encontros coletivos para discutir e decidir sobre as questões trazidas pelo trabalho), a forma de entrada e saída das componentes, o manejo de bens comuns (desde a compra e venda de equipamentos até a constituição de fundos comuns para garantir a possibilidade de planejar o futuro e se proteger dos revezes). No caso deste tipo de normas, é mais recorrente a iniciativa para tratar deliberadamente de sua formulação e também a demanda para que as regras sejam enunciadas, inclusive na forma escrita.

No curso das diferentes experiências com os grupos, a nossa forma de entender o papel que um documento escrito pode representar neste processo foi mudando. No caso do grupo Copermasol, este era um objetivo enunciado desde o início e finalmente atingido. $\mathrm{O}$ amadurecimento das reflexões e a observação da dinâmica do grupo nos revelou, no entanto, dois problemas neste processo. O que se observou é que o documento escrito, depois de pronto, não era de regra acessado pelas trabalhadoras. Nas poucas ocasiões em que percebi isto acontecer, o texto foi apropriado pelas trabalhadoras com maior formação escolar (e maior domínio da leitura do texto escrito), para extrair dele interpretações que lhes favoreciam. O grupo havia decidido, por exemplo, que as trabalhadoras que fariam as compras da matéria-prima receberiam uma remuneração maior, em virtude da complexidade e tempo exigido pela tarefa. O que se demonstrou, no entanto, é que aos poucos as pessoas incumbidas das compras passaram a acumular uma remuneração exageradamente superior, em uma situação que pode ser, sob determinado olhar, considerada injusta. Por vezes a discussão sobre o assunto foi evitada, sob o argumento de que 'isto já ficou decidido nas regras' (Pita 2015: $52)$.

Em segundo lugar, nos demos conta de como era importante a forma como se "registrava" as regras. Se a intenção é garantir uma memória sobre as discussões e decisões do grupo, de modo que elas possam ser acessadas facilmente e utilizadas para solucionar os impasses da convivência, este registro deve ser capaz de comunicar bem. Assim, o modo de traduzir a linguagem oral para a linguagem escrita deveria respeitar, o tanto quanto possível, as formas da oralidade, evitar termos técnicos, inversões sintáticas, palavras estranhas ao vocabulário popular - enfim, tudo que pudesse dificultar a leitura. Uma outra proposta, que está sendo cogitada para os casos dos grupos Sabores do Quilombo e Delícias da Formiga, aponta para uma mudança na forma de registro. Considerando o uso disseminado dos smartphones (e aplicativos como o Whatsapp) entre as trabalhadoras, pensamos transformar o registro escrito em arquivos de áudio curtos, que poderiam ser compartilhados facilmente e acessados sempre que necessário. 
A reflexão quanto à forma de registro nos conduziu, então, a uma outra questão mais ampla: seria mesmo oportuno "finalizar" as regras, produzindo um "algo" (escrito ou oral), um corpo de normas que funcionam como um "instituído" final?

A enunciação deliberada das regras em um documento (seja escrito ou oral) parece produzir efeitos ambivalentes. Por um lado, tem um efeito agregador, favorecendo a construção de uma identidade para o grupo e a prevenção e a mediação de conflitos. É perceptível, pelas falas das trabalhadoras, o desejo de "acabar as regras": este ponto final parece assumir um sentido de ponto de início, o instituído fundador do grupo, a sua "constituição". Por outro lado, o descompasso entre a realidade vivida, sempre em mutação, e as regras, enrijecidas no documento escrito, também favorece as dinâmicas de diferenciação de poder no âmbito do grupo, a partir de vantagens pessoais (as melhores oradoras, as menos tímidas, as que dominam a leitura), o que vai no sentido contrário da efetiva horizontalidade e intensidade da autogestão. Este processo, portanto, deve ser pensado com cuidado, respeitando-se as peculiaridades do grupo (grau de escolaridade, intimidade entre as trabalhadoras, formas peculiares de exercício interno do poder). Neste sentido, ainda, percebemos que a enunciação das regras que chamei de "extraordinárias" parece ter um efeito mais positivo para a convivência do grupo que a das regras "ordinárias", o que deve ser levado em consideração, em cada caso, para escolher o conteúdo do documento que se deseje produzir, se for o caso.

Dardot e Laval, discutindo o comum enquanto instituição, intuem que "cada comum deve ser instituído por uma prática que abra certo espaço ao definir as regras de seu funcionamento" (2017: 618). A partir de seu conceito de práxis instituinte, os autores parecem corroborar as conclusões a que vimos chegando, propondo que este ato de instituição inicial (relacionado aqui, num viés mais pragmático, ao registro das "regras de convivência" das trabalhadoras) "deve continuar para além do ato pelo qual o comum é criado. Deve ser sustentada ao longo do tempo por uma prática que tenha a possibilidade de modificar as regras por ela própria estabelecidas” (2017: 618).

Por sua vez, ao tratar do caso da Central Cooperativa de Servicios Sociales Lara (CECOSESOLA), longeva e bem sucedida organização cooperativa venezuelana (rede cooperativa que proporciona diferentes tipos de ligação entre produtores e consumidores, espaços de comercialização, serviços cooperativos de saúde, por exemplo), Raquel Gutiérrez Aguilar destaca que:

Lo más interesante [...] es su funcionamiento interno y el sistemático esfuerzo realizado por no ser únicamente una «organización» en el sentido rígido que suele asignarse a tal noción: propósitos explícitos - y por lo tanto acotados -, estatutos definidos rigurosamente, modos de funcionamiento instituidos como procedimientos generales, etc. Son «organización en movimiento» en tanto una de las actividades internas que con más cuidado cultivan y cuidan es la reunión colectiva y la conversación (2017: 104). 
A noção de "organização em movimento" (como se autodefine a CECOSESOLA) é contraposta à de instituição na sua versão liberal-estatal, que remete a um momento instituidor reificado no tempo e no espaço (o Estatuto, o Contrato, a Constituição). Observo que o movimento adjetiva a organização, mas não a nega - a CECOSESOLA "não é unicamente uma organização", mas ainda o é. Pensar na simultaneidade e equilíbrio entre permanências e movimentos, em essência e contingência parece ser uma chave para dosar a centralidade que podem assumir as "regras de convivência" ("extraordinárias" e as "ordinárias") na produção do comum, de modo que elas possam ser auxiliares, e não obstáculos, dos "cotidianos y persistentes esfuerzos para seguir produciendo su existencia con base en refrendar acuerdos colectivos una y otra vez, establecer límites internos y externos de las prácticas admisibles, mejorar y perfeccionar prácticas de colaboración y «resolución» de conflictos internos, etc." (Gutiérrez 2017: 104). Este parece ser um caminho para aproximar o fazer comum (e o seu Direito) do próprio ritmo da vida.

Tudo isso nos faz pensar na importância de reforçar o caráter mutável das regras, bem como em exercitar práticas democráticas para sua alteração e interpretação diante do caso concreto. Incentivar-se, por exemplo, mesmo no documento final, a previsão de momentos de rediscussão periódica das regras, como aconteceu no caso da Feira de Sabores e Sabores:

6.1 Estas regras podem ser alteradas pelo próprio grupo em decisão coletiva de pelo menos 75\% (três quartos) das iniciativas presentes na reunião que tiver este objetivo.

6.2 De todo modo, a cada ano, estas regras serão objeto de leitura e rediscussão coletiva, com o objetivo de atualização e melhoramento a partir das práticas e vivências do coletivo que as criou.

A simples “ordem” para rediscussão periódica das regras não é suficiente, por certo - é um mero detalhe em um universo muito maior de questões. Trata-se de um exercício coletivo que pretende uma transformação muito mais profunda e complexa. Cuida-se de desejos, de escolhas, em outros modos de se exprimir corporalmente em relação aos(às) outros(as) - olhar, escutar, modular a entonação da voz, tocar -, da forma de repartir o tempo entre as diferentes atividades, de entender o sentido da liberdade, desejar e fazer escolhas. O que temos tentado fazer é persistir no caminho deste aprendizado.

\section{CONCLUSÃO:}

Acreditamos, com Bruno Cava, que devemos nos concentrar, sobretudo "nas potencialidades e oportunidades, muitas vezes fugidias, espontâneas, mais ou menos conscientes, de reinvenção e revolta ante as formas capitalistas", o que nos faz ter que "descer ao nível dos lugares e tempos em que o trabalho vivo acontece, para pesquisar elementos de autonomia que possam ser 
organizados, entretecidos e propagados" (2012: 61). É neste sentido que as "Regras de Convivência" têm sido objeto de experiências e reflexões compartilhadas com as trabalhadoras dos projetos desenvolvidos pela IEPS-UEFS.

As "Regras de Convivência" são tomadas por nós como parte do esforço de elaboração do comum, a partir do fazer autogestionário, e assumidas como Direito - no sentido de que, muito mais do que simples manifestações de moralidade ou técnica, estabelecem um espaço comum de produção, decisão e execução de ideias e ações coletivas, fundamental para a autonomia identitária e política de cada trabalhadora em relação ao grupo e do próprio grupo enquanto um corpo social organizado.

O processo de produção das regras do grupo tem uma dinâmica diretamente relacionada aos conflitos que caracterizam o encontro coletivo de diferentes subjetividades, especialmente quando isto se dá no âmbito da autogestão. O conflito, aqui, assume um sentido ambíguo: se por um lado é um signo de autonomia, por outro é um elemento corrosivo do sentido e prazer do esforço pelo comum. Entendemos que o exercício de explicitar, discutir, formular e reformular coletivamente as regras que unem o grupo pode ser um elemento importante na busca pelo equilíbrio do papel do conflito no trabalho coletivo que almeja ser horizontal, democrático, solidário - que luta para fazer da fórmula jurídica marxiana "de cada um segundo suas capacidades, a cada um segundo suas necessidades” (MARX 2012: 33) a máxima de um outro Direito.

\section{REFERÊNCIAS:}

AGUILAR, Eduardo Enrique. 2018. ¿De qué hablamos cuando décimos outra economia es polible? Reflexiones sobre las economías solidarias y los polibles significados de la transición. Otra Economía 11(20): 88-100

BARBIER, René. 2007. A Pesquisa-Ação. Brasília: Liber.

BRANDÃO, Carlos Rodrigues. 1984.Repensando a Pesquisa Participante. São Paulo: Brasiliense.

BRANDÃO, Carlos Henrique. 2007. A pesquisa participante: um momento da educação popular. Revista Educação Popular. 6: 51-62.

CASTRO-GÓMEZ, Santiago. 2005. La hybris del punto cero : ciencia, raza e ilustración en la Nueva Granada (1750-1816). Bogotá: Editorial Pontificia Universidad Javeriana.

CAVA, Bruno. 2012. A coruja voa de tarde: a ontologia comunista do fazer-se da multidão. Revista Eco-Pós 15 (2): 51-68.

COELHO, Luiz Fernando. 1987. Teoria Crítica do Direito. Curitiba: Livros HDV. 
DARDOT, Pierre. LAVAL, Christian. 2017. Comum: ensaio sobre a revolução no século XXI. São Paulo: Boitempo.

FALS BORDA, Orlando. 2009. Uma sociología sentipensante para América Latina. Colombia: Clacso, 2009.

FEDERICI, Silvia. 2017. Calibã e a bruxa: mulheres, corpo e acumulação primitiva. São Paulo: Elefante.

GAGO, Veronica. 2018. A razão neoliberal: economias barrocas e pragmática popular. São Paulo: Elefante.

GUTIÉRREZ AGUILAR, Raquel. 2017. Horizontes comunitario-populares: producción de lo común más allá de las políticas estado-céntricas. Madrid: Traficantes de Suenõs.

HARDIN, Garrett. 1968. The Tragedy of the Commons 1968. Science 162: 1243-1248.

HARDT, Michael. NEGRI, Antonio. 2016. Bem-estar comum. Rio de Janeiro: Record.

HART, Keith. 1973. Informal income opportunities and urban employment in Ghana. The Journal of Modern African Studies, 11 (1): 61-89.

HOLLOWAY, John. 2013. Fissurar o capitalismo. São Paulo: Publisher Brasil.

HORKHEIMER, Max. 1983. Teoria Tradicional e Teoria Crítica. In: BENJAMIN, Walter;

HORKHEIMER, Max; ADORNO, Theodor W.; HABERMAS, Jürgen. Textos escolhidos. (Col. Os Pensadores, Vo. XLVIII). São Paulo: Abril Cultural, pp. 117-161.

IEPS-UEFS - INCUBADORA de Iniciativas da Economia Popular e Solidária da UEFS. 2011. Carta de Princípios. Feira de Santana. Disponível em:

<http://incubadorauefs.blogspot.com.br/p/carta-de-principios.html>BRA>. Acesso em: 26 mai. 2019.

LECHAT, Noëlle Marie Paule. 2002. As raízes históricas da economia solidária e seu aparecimento no Brasil. Palestra proferida na Unicamp por ocasião do II Seminário de Incubadoras Tecnológicas de Cooperativas Populares, em 20 mar. 2002. Disponível em:

<http://www.itcp.usp.br/drupal/node/250>. Acesso em: 13 nov. 2013.

LINSALATA, Lucia, 2011. Valor de uso, poder y transformación social. Serie de cuadernos: Entender la descomposición. Vislumbrar las posibilidades, n.3. Casa de Ondas: México D.F.

LINSALATA, Lucia. SALAZAR, Huáscar. 2015. Introducción. El Apantle 1: 9-14.

LYRA FILHO, Roberto. 1982. Normas Jurídicas e outras Normas Sociais. Direito e Avesso 1(1): 49-57.

LYRA FILHO, Roberto. 1983. Karl, meu amigo: diálogo com Marx sobre o Direito. Porto Alegre: Sergio Antonio Fabris.

LYRA FILHO, Roberto. 1986. O que é Direito. Coleção Primeiros Passos. São Paulo: Brasiliense. 
MARX, Karl. 1978. O Capital, livro I, capítulo VI (inédito). São Paulo: Livraria Editora Ciências Humanas Ltda.

MARX, Karl. ENGELS, Friedrich. 2007. Manifesto Comunista. São Paulo: Boitempo.

MARX, Karl. 2012. Crítica do Programa de Gotha. São Paulo: Boitempo.

MARX, Karl. 2017. O Capital: crítica da economia política - livro I. 2. ed. São Paulo: Boitempo.

MIAILLE, Michel. 2005. Introdução Crítica ao Direito. Lisboa: Estampa.

NAVARRO, Mina Lorena. 2012. Las luchas socioambientales en México como una expresión del antagonismo entre lo común y el despojo múltiple. OSAL- CLACSO 32: 150-171.

OLIVEIRA, Emile Lima. PITA, Flávia Almeida. 2017. A busca da formalização jurídica como mecanismo de consolidação das iniciativas de economia popular e solidária. Revista Vox 6: 31-35.

PACHUKANIS, Evguiéni B. 2017. Teoria Geral do Direito e Marxismo. São Paulo: Boitempo. PASSOS, J. J. Calmon de. 1999. Direito, poder, justiça e processo: julgando os que nos julgam. Rio de Janeiro: Forense.

PAZELLO, Ricardo Prestes. 2014. Direito Insurgente e Movimentos Populares: o giro descolonial do poder e a crítica marxista ao direito. Tese (Doutorado em Direito) Programa de Pós-Graduação em Direito, Setor de Ciências Jurídicas, da Universidade Federal do Paraná.

PERES, Thiago Brandão. 2015. Informalidade: um conceito em busca de uma teoria. Revista da ABET 14(2): 270-289

PITA, Flávia Almeida. 2015. Construção autogestionária de normas para a convivência no trabalho cooperado: reflexões a partir de uma experiência. Anais do $5^{\circ}$ Seminário Interdisciplinar em Sociologia e Direito. Niterói: PPGSD-UFF, pp. 41-55.

PITA, Flávia Almeida. 2017. Economía solidaria y derecho: reflexiones a partir de la cuestión de la formalización jurídica de los grupos de economía solidaria. In: MEYER, Raúl González. Ensayos sobre Economía Cooperativa, Solidaria e Autogestionaria: hacia una economía plural. Santiago: Editorial Forja, pp 229-253.

PITA, Flávia Almeida. 2018. Economia solidária e Direito: reflexões a partir da questão da formalização jurídica dos grupos de economia popular solidária. Revista Vox 7: 26-48.

SANTOS, Liziany Cerqueira. 2014. Caminhos para a solução de conflitos no contexto da Economia Popular e Solidária. Acta Científica $8^{\circ}$ Congreso Chileno de Sociología 2014 y Encuetro Pre-Alas 2015. La Serena, Chile: Asociación Latinoamericana de Sociologia.

SILVA, Vera Letícia de Oliveira. 2016. A mediação de conflitos como ferramenta do trabalho solidário e autogestionário OLIVEIRA, David. SILVA, Artur Stamford da. CARVALHO, Paulo. PIRES, Carolina Leal (orgs.). A Sociologia do Direito entre discurso e ação. v. 2 Porto Alegre: ABRASD, pp. 261-272. 


\section{AUTORA:}

Flávia Almeida Pita

Doutoranda do Programa de Pós-Graduação em Sociologia e Direito da Universidade Federal Fluminense. Professora da Universidade Estadual de Feira de Santana. Integrante da Incubadora de Iniciativas da Economia Popular e Solidária da UEFS. Procuradora do Estado da Bahia.

E-mail: fa-pita@uol.com.br 